\title{
Proyectos de desarrollo turístico y consulta previa: el caso del pueblo raizal en Colombia
}

\author{
Touristic development projects and prior consultation: \\ The case of the raizal people in Colombia
}

\section{Silvia Morón Castañeda*}

Fecha de recepción: 12 de octubre de 2018

Fecha de aprobación: 18 de enero de 2019

\section{RESUMEN}

Los proyectos de desarrollo turístico se han convertido en uno de los principales motores del progreso económico de países como Colombia, lo cual llama la atención de inversionistas interesados en determinadas zonas por su riqueza natural y cultural. A raíz de esto se han generado múltiples conflictos socioambientales debido a los permisos, autorizaciones y licencias que las autoridades nacionales han otorgado para el desarrollo de dichos emprendimientos. Sumado a lo anterior no ha sido valorado en su justa medida el derecho a consultar previamente a los miembros de grupos étnicos protegidos por el Estado y a la participación de estos en la toma de decisiones.

* El presente documento es producto del proyecto de investigación "Proyectos de desarrollo turístico y consulta previa: el caso del pueblo raizal en Colombia", realizado en el marco de la Maestría en Derecho de la Facultad de Jurisprudencia de la Universidad del Rosario, Bogotá. Citar como Morón Castańeda, S. (2019). Proyectos de desarrollo turístico y consulta previa: el caso del pueblo raizal en Colombia. Via Inveniendi et Iudicandi, 14(2), 35-64. DOI: https://doi.org/10.15332/19090528.5045

** Abogada y especialista en Derecho Administrativo. Estudiante de Maestría en Derecho con énfasis en DD. HH. y Justicia Transicional de la Facultad de Jurisprudencia de la Universidad del Rosario, Bogotá. Asesora independiente en temas de derecho disciplinario y contractual de la Universidad Nacional, Bogotá. Correo electrónico: simorca1@gmail.com. Orcid: https://orcid.org/0000-0001-6619-4803 
La Corte Constitucional de Colombia mediante Sentencia T-800/2014 decidió un caso emblemático del pueblo raizal asentado en el municipio insular de Providencia y Santa Catalina, del departamento Archipiélago de San Andrés, Providencia y Santa Catalina, el cual solicitó el amparo de su derecho fundamental a la consulta previa por la realización del proyecto turístico Spa Providencia.

Palabras clave: proyectos de desarrollo, turismo, consulta previa, pueblo raizal.

\section{Abstract}

Projects on Tourism development have become one of the main generators of economic progress in countries like Colombia. They captivate the attention of investors interested in in certain areas that are naturally and culturally rich. Nonetheless, multiple socioenvironmental issues have been created due to the permits, authorizations and licenses that national authorities have granted for the development of these endeavors. In addition, there is lack of consultation to members of ethnic groups that are directly affected and should have the right to be previously consulted. Hence, their participation in decision-making has not been adequately assessed.

The Constitutional Court of Colombia by means of Sentence T-800 of 2014, decided an emblematic case about the raizal people settled in the island municipality of Providencia y Santa Catalina of the Archipiélago de San Andrés, Providencia y Santa Catalina province, is analyzed. It requested the protection of its fundamental right to prior consultation for the realization of the tourist project Spa Providencia.

Keywords: Development projects, turism, prior consultation, raizal people. 


\section{INTRODUCCIÓN}

Para el momento de implementación del Plan Nacional de Desarrollo 2014-2018 se dispuso que el sector turístico enfrentaba limites de diverso tipo en su oferta, de acuerdo con lo contemplado en el reporte de Competitividad de Viajes y Turismo realizado por el Foro Económico Mundial (FEM) en 2013. En efecto, este señalaba que Colombia se encontraba ubicada en la posición 84 entre 140 países, y ocupaba el séptimo puesto entre 10 países de Sudamérica, situándose en ese momento por debajo de Brasil, Chile, Uruguay, Argentina, Perú y Ecuador (DNP, 2015, p. 92).

En la experiencia adquirida por el Ministerio de Comercio, Industria y Turismo (Mincit) en la ejecución de la política de turismo, se identificaron problemáticas relacionadas con el desarrollo de la actividad y su materialización en las regiones: 1) baja calidad de los servicios turísticos que impide cumplir con estándares internacionales; 2) deficiencias de la planta turística así como de la infraestructura que limitan el desarrollo de destinos turísticos; 3) bajos niveles de conectividad aérea, marítima, fluvial y digital entre las regiones; 4) limitada aplicación de políticas nacionales en las regiones e inaplicabilidad de planes de desarrollo turístico a nivel local; 5) ausencia de coordinación entre las entidades del orden nacional en torno a las políticas del sector: y, 6) pérdida de articulación y manejo de los recursos públicos por parte del Mincit. (DNP, 2015, p. 117)

Por esta razón el Gobierno de Juan Manuel Santos incentivó la inversión nacional y extranjera de empresas interesadas en desarrollar proyectos turísticos en el país con la intención de que Colombia sea "un país con empresas pujantes, social y ambientalmente responsables que conquisten los mercados internacionales con bienes y servicios de alto valor agregado e innovación; un país integrado a la economía mundial, con una infraestructura y un entorno de competitividad" (Rodríguez, 2014, pp. 23-24).

No obstante las intenciones gubernamentales, se han presentado confrontaciones entre las empresas y los miembros de grupos étnicos, tanto indígenas como raizales, 
por ser ellos quienes en muchos casos ocupan los espacios geográficos en los cuales se desarrollan, o se pretende desarrollar, proyectos de carácter turístico.

$\mathrm{Al}$ respecto los empresarios consideran limitada la posibilidad de invertir y desarrollar sus actividades comerciales en virtud de la "tramitología" para efectos de obtener las licencias ambientales, toda vez que consultar previamente y bajo parámetros específicos a los miembros de las minorías étnicas directamente involucradas con la materialización de la actividad turística a emprender implica obligaciones adicionales para el titular del proyecto. A ello se suma el hecho de que en ocasiones las licencias son autorizadas aparentemente de manera legal, pero por desconocimiento o negligencia de las autoridades estatales otorgantes no se garantiza adecuadamente el derecho a la participación, y por ende, se suele incurrir en violaciones de los derechos fundamentales y colectivos de dichos grupos.

Por otro lado, las comunidades étnicas, entre ellas los grupos raizales y los pueblos indígenas, sienten vulnerados sus derechos al observar que sus costumbres, su cosmovisión, sus espacios sagrados y su territorio no resultan suficientemente valorados por parte de las autoridades estatales. Aquellas argumentan que estas últimas, que tienen el deber de proteger sus culturas, conceden licencias ambientales a empresas interesadas en invertir en territorios de especial protección sin dar cumplimiento a uno de los requisitos fundamentales para su otorgamiento: la realización de la consulta previa a los grupos étnicos directamente afectados.

Una muestra de estas confrontaciones se hizo visible entre los intereses empresariales privados, en conjunto con los del gobierno de la época, y los miembros del pueblo raizal providenciano respecto de la construcción del proyecto turístico Spa Providencia, en cabeza del Mincit (Ministerio de Comercio, Industria y Turismo), en el municipio insular de Providencia y Santa Catalina, del departamento Archipiélago de San Andrés, Providencia y Santa Catalina. En ese contexto las entidades públicas, principalmente el Mincit, vulneraron derechos de carácter fundamental al no llevar a cabo la consulta previa al referido grupo raizal, en un territorio declarado por la Unesco como Reserva de la Biosfera, y otorgar sin el cumplimiento de este requisito la licencia ambiental para construir el proyecto turístico citado. 
En consecuencia, una vez superadas varias instancias de carácter judicial por parte del pueblo raizal, se expide la Sentencia T-800/2014. La Corte Constitucional consideró allí que tanto la actitud omisiva de las autoridades administrativas como los argumentos contemplados por los órganos judiciales resultaban errados frente a la violación flagrante del derecho fundamental a la consulta previa y a la integridad cultural de los miembros del mencionado grupo étnico.

En aras de entender las fuentes de está problemática el presente artículo analizará, en primer lugar, los conceptos de turismo, proyectos de desarrollo turístico, ecoturismo y turismo sostenible, su relación con el concepto de territorio y su impacto en materia de derechos humanos. En segundo lugar, se definirá el concepto de consulta previa tanto desde el punto de vista teórico como jurisprudencial, y se evaluará cómo ese derecho se debería garantizar para el pueblo raizal. Finalmente, se examinarán el caso del proyecto turístico Spa Providencia y las órdenes de la Sentencia T-800/2014 de la Corte Constitucional para extraer algunas conclusiones.

\section{Planteamientos teórico-ConCeptuales sobre ecoturismo, TURISMO SOSTENIBLE Y SU RELACIÓN CON LOS TERRITORIOS Y LOS DERECHOS HUMANOS}

La Organización Mundial del Turismo (OMT, 1994) define este concepto como el

fenómeno social, cultural y económico relacionado con el movimiento de las personas a los lugares que se encuentran fuera de su residencia habitual por motivos personales o de negocios/profesionales, con efectos en la economía, en el entorno natural y en las zonas edificadas, en la población local de los lugares visitados y en los visitantes propiamente dichos.

En ese sentido, el desarrollo turístico es considerado como la provisión y el mejoramiento de las instalaciones y los servicios idóneos para satisfacer las necesidades del turista, incluidos sus efectos asociados, como la creación de empleos o la generación de ingresos (Pearce, 1991; citado en Varisco, 2008, p. 61). Tal desarrollo puede subdividirse en dos partes: la primera refiere a la estructura socioproductiva 
que en los centros receptores permite al visitante disfrutar de los recursos que han motivado su desplazamiento; la segunda, al impacto económico de la actividad turística que genera ingresos provenientes de la creación de empleos y el comercio, entre otros (Varisco, 2008).

Sin embargo, esta situación representa un desafío para todos los actores implicados en buscar soluciones a los problemas que puedan generarse por la actividad turística, quienes han de buscar la manera de encauzar y orientar adecuadamente el logro de sus objetivos (Brida, Monterubbianesi y Zapata-Aguirre, 2011, p. 292). En efecto, se trata de una actividad económica con un impacto significativo para los intereses sociales, ambientales, políticos y culturales de un país. A fin de que sus objetivos se materialicen cabalmente resulta imprescindible que el turismo se lleve a cabo en el marco del desarrollo sostenible.

En 2004 el Comité de Desarrollo Sostenible del Turismo de la OMT dispuso que las directrices para el desarrollo sostenible de esta actividad y las prácticas de gestión sustentable son aplicables a todas las formas de turismo en todos los tipos de destinos, incluidos el turismo de masas y los diversos segmentos turísticos. De acuerdo con la Declaración de Río sobre el Medio Ambiente y el Desarrollo de 1992, la sostenibilidad se refiere al logro del equilibrio entre tres dimensiones, a saber: ambiental, económica y social, las cuales deben ser consideradas en el desarrollo turístico a largo plazo (Cortés, 2016).

El desarrollo sostenible del turismo exige la participación informada de todos los agentes relevantes, así como un liderazgo político firme para lograr una colaboración amplia. El logro de un turismo sostenible es un proceso continuo y requiere un seguimiento constante de los impactos que genera para introducir las medidas preventivas o correctivas que resulten necesarias. (OMT, 2004)

Los proyectos de desarrollo turístico son considerados de infraestructura social por incentivar el progreso económico del lugar donde se llevan a cabo. No obstante, se ha considerado que la planeación y desarrollo turístico ha resultado ineficaz en su práctica debido a que no ha contribuido contundentemente al desarrollo de países como Colombia. Por eso resulta impostergable remover los estrangulamientos, cuellos de 
botella y errores de procedimiento cometidos procurando evitar su reincidencia en el futuro y afrontando el porvenir con nuevos propósitos, ideas y sobre todo acciones concretas (Gómez Tobón, 2002, p. 67).

Estas situaciones son generadas en gran parte porque, con la realización de cualquier tipo de proyecto y especialmente para el caso de proyectos turísticos, los inversionistas inciden directamente en las actividades cotidianas de la zona donde se ejecutan. $Y$ en ocasiones lo hacen en las actividades tradicionales que realizan las comunidades locales o grupos étnicos sin prever o divulgar el tipo de afectación económica, social y ambiental a causar o causada (Rodríguez, 2014, p. 120).

De este modo, se presentan oportunidades de mejoramiento en el desarrollo de políticas asociadas al turismo, pero promoviendo megaproyectos de infraestructura hotelera inviables por ubicarse en ecosistemas ambientalmente sensibles. O se promueve un turismo ecológico y cultural igualmente gestionado por grandes monopolios que reducen a los grupos étnicos a un mero atractivo turístico (Romero et al., 2016, p. 138).

Este tipo de actividades que incrementan el desarrollo económico del país no deberían verse obstaculizadas, pero tampoco ocasionar afectaciones que conlleven la vulneración de derechos fundamentales o colectivos de comunidades, grupos o pueblos directa o indirectamente involucrados. Por eso los dueños de los proyectos deben realizar evaluaciones de impacto ambiental para definir las correspondientes medidas de prevención, corrección, compensación y mitigación de impactos y efectos negativos de sus obras (Rodríguez, 2014, p. 121).

De igual manera, es necesario inyectar recursos económicos reales y suficientes en planes, programas y proyectos definidos y concertados, que cumplan con exigencias precisas de impacto y eficiencia económica y social. Igualmente, ha de propiciarse una vinculación efectiva de las comunidades receptoras a la dinámica turística local y regional, de modo que se contribuya directamente con el desarrollo colombiano (Gómez Tobón, 2002, p. 67). 


\section{Ecoturismo}

Ha sido definido por la UICN (Unión Internacional para la Conservación de la Naturaleza) como

aquella modalidad turística ambientalmente responsable, consistente en viajar o visitar áreas naturales relativamente sin disturbar con el fin de disfrutar, apreciar y estudiar los atractivos naturales (paisaje, flora y fauna silvestres) de dichas áreas, así como cualquier manifestación cultural (del presente y del pasado) que puedan encontrarse ahí, a través de un proceso que promueve la conservación. Tiene bajo impacto ambiental y cultural y propicia un involucramiento activo y socioeconómicamente benéfico de las poblaciones locales. (García Hernández, 2013, p. 105)

En la legislación colombiana la Ley 300 de 1996, Ley General de Turismo, contempla el ecoturismo como "una actividad controlada y dirigida que produce un mínimo impacto sobre los ecosistemas naturales, respeta el patrimonio cultural, educa y sensibiliza a los actores involucrados acerca de la importancia de conservar la naturaleza" (art. 26).

De igual manera, y bajo la opinión de algunos doctrinantes, el ecoturismo debe ser entendido no solo como una actividad permitida, sino como una estrategia de conservación para las áreas protegidas con vocación turística del SPNN (Sistema de Parques Nacionales Naturales) (Cubillos, González, Díaz, Ruiz y Jiménez, 2013, p. 17).

\section{Turismo sostenible}

La OMT lo ha definido desde 1988 como el turismo que tiene plenamente en cuenta las repercusiones económicas, sociales y ambientales actuales y futuras para satisfacer las necesidades de los visitantes, la industria, el entorno y las comunidades anfitrionas. En este sentido, el trabajo de la OMT se centra en los tres objetivos de la sostenibilidad: la protección ambiental, la equidad y la cohesión de la sociedad, y la prosperidad económica (Cortés, 2013). 
Bajo este criterio el turismo sostenible ha sido considerado por Swarbrooke (1999) como aquel económicamente viable, pero que no destruye los recursos de los que dependerá su propio futuro, en particular el ambiente físico y el tejido social de la comunidad anfitriona.

Al respecto, la Constitución Política de Colombia de 1991 ha previsto a través de su art. 79 que todas las personas tienen el derecho a gozar de un ambiente sano, y por medio de su art. 80, que el Estado se compromete a planificar el manejo y aprovechamiento de los recursos naturales para garantizar su participación en el desarrollo sostenible y su conservación, restauración o sustitución. Lo anterior con el fin de velar por la calidad de vida de sus habitantes y su entorno. Por su parte, la Ley 99 de 1993, conocida también como Ley General Ambiental, dispone en su art. 1, num. 2, que la biodiversidad del país, por ser patrimonio nacional y de la humanidad, deberá ser protegida prioritariamente y aprovechada en forma sostenible (Humbarita, 2015).

Así mismo, la Ley 21 de 1991, "Por medio de la cual se aprueba el Convenio número 169 sobre pueblos indígenas y tribales en países independientes, adoptado por la $76^{\mathrm{a}}$ reunión de la Conferencia General de la OIT, Ginebra 1989”, establece en su art. 7 que

los pueblos interesados deberán tener el derecho de decidir sus propias prioridades en lo que atañe al proceso de desarrollo, en la medida en que este afecte a sus vidas, creencias, instituciones y bienestar espiritual y a las tierras que ocupan o utilizan de alguna manera, y de controlar, en la medida de lo posible, su propio desarrollo económico, social y cultural.

Con base en los planteamientos normativos previamente expuestos se tiene que frente al desarrollo de proyectos turísticos es imprescindible cumplir con parámetros mínimos que propendan a un manejo adecuado de la biodiversidad y a la sostenibilidad del medio ambiente a través de la convocatoria de los actores vinculados directa e indirectamente al sector turístico en el terreno de intervención del proyecto. En ese orden de ideas también es importante la obtención de información idónea a través de dichos actores, que lleve a establecer qué, cómo, dónde, cuándo y por qué se 
considera que dicha actividad contribuye al desarrollo de la comunidad. Así mismo resulta relevante la planificación adecuada en la utilización de los recursos naturales, el uso del territorio y el tratamiento apropiado de minorías (indígenas, raizales, entre otros) que se encuentren asentadas y puedan verse afectadas con la realización de este tipo de iniciativas de desarrollo económico en las regiones.

\section{El IMPACTO DE LOS PROYECTOS DE DESARROLLO TURÍSTICO SOBRE LOS TERRITORIOS Y LOS DERECHOS HUMANOS DE LAS COMUNIDADES}

La Declaración Americana de Derechos Humanos de 1948, en su art. 23, y la Convención Americana de Derechos Humanos de 1969, en el art. 21, establecen el derecho de propiedad entendiéndolo como la relación de los pueblos indígenas y tribales (entre los segundos se hallan los grupos étnicos raizales) con la tierra y los recursos naturales de los territorios ancestrales.

Al respecto la Corte Interamericana de Derechos Humanos ha manifestado insistentemente que los Estados deben respetar la relación fundamental de los miembros de los pueblos indígenas y tribales (raizales) con su territorio, como modo de proteger y garantizar su supervivencia social, cultural y económica. Esta especial relación ha sido ampliamente reconocida en el derecho internacional de los DD. HH. así como a nivel nacional (CIDH, 2010, pp. 21-22).

Incluso a nivel nacional, como se verá en la cuarta sección de este artículo, la Corte Constitucional colombiana (Sentencia T-849/2014, p. 24) consideró que los miembros de los grupos raizales sostienen una relación con la isla y el territorio tanto económica como de carácter cultural y ambiental.

En consecuencia, los esfuerzos internacionales han estado orientados principalmente a definir las normas de derechos humanos aplicables a las empresas en la ejecución de proyectos de desarrollo económico. Al respecto, John Ruggie, en un informe presentado en 2011 al Consejo de Derechos Humanos de la Organización de las Naciones Unidas, señaló algunos principios relacionados con el modo más idóneo de protección de ese tipo de derechos. Así, dicho Consejo acogió unánimemente en 
su Resolución 17/4 los Principios rectores sobre las empresas y los derechos humanos para "proteger, respetar y remediar" los daños causados en el ejercicio de sus actividades comerciales.

Estos Principios rectores son en la actualidad la referencia mundial para todos los actores (principalmente los Estados, las empresas y la sociedad civil) que de forma directa o indirecta tienen obligaciones, responsabilidades o intereses legítimos en relación con la actividad comercial y empresarial (Rivera, 2016).

No obstante, en ese conjunto de principios no se contemplan preceptos jurídicos vinculantes mediante los cuales se señale puntualmente el modo de prevención, corrección y posterior sanción, aplicable dependiendo del caso, a las empresas o Estados que en el ejercicio de sus actividades generen algún tipo de afectación a terceros por acción u omisión.

Por eso a la fecha los lineamientos en materia de proyectos turísticos se basan esencialmente en lo contemplado en la ley, la Constitución y los tratados internacionales ya que los principios planteados por Ruggie son apenas un proyecto que aún no se ha materializado (López, 2015, p. 5).

Mientras esta importante iniciativa logra concretarse las autoridades ambientales, por mandato constitucional y legal, tendrán la potestad para tomar las decisiones finales al momento de otorgar licencias ambientales que permitan a los inversionistas desarrollar proyectos turísticos en el país sin menoscabo de las condiciones del medio natural. Por tanto, tendrán igualmente el deber de facilitar y fomentar la sensibilización y la participación de la población poniendo la información a disposición de todos, disminuyendo y removiendo todo tipo de restricciones y barreras y proporcionando el acceso efectivo a los procedimientos administrativos. De aquí el valor de establecer un marco de acción y buenas prácticas que permita a las autoridades ambientales garantizar la participación en estos procesos y lograr así decisiones más acertadas, legitimadas por el consenso social y con mayor transparencia en la gestión de los asuntos públicos (Betancur, citado en Güiza y Gutiérrez, 2012, p. 92). 


\section{EL DERECHO A LA CONSULTA PREVIA Y EL GRUPO ÉTNICO RAIZAL}

Los proyectos turísticos en muchas ocasiones se encuentran ubicados en territorios ocupados por grupos de especial protección constitucional y dotados de una gran riqueza en términos de biodiversidad. De allí que tales emprendimientos deban garantizar altos estándares económicos, sociales y ambientales que materialicen los conceptos de ecoturismo y turismo sostenible y eviten vulneraciones de derechos humanos.

De esta manera, es indispensable la participación de las comunidades directa o indirectamente impactadas por los proyectos. En el caso de los grupos étnicos esta prerrogativa se materializa a través del derecho fundamental a la consulta previa, el cual constituye la herramienta más importante para la protección y el respeto de otros derechos conexos, como la integridad cultural, el territorio y la propiedad privada, entre otros.

\section{El derecho a la consulta previa y su conceptualización jurídica}

El derecho a la consulta previa se encuentra bajo el amparo de preceptos normativos tanto de carácter nacional como internacional en lo que se refiere a los miembros de los grupos étnicos reconocidos en Colombia -indígenas, raizales, afrodescendientes, rom y palenqueros - que puedan verse afectados por las distintas determinaciones políticas, administrativas, legislativas o judiciales que involucren aspectos tales como su cosmovisión, su cultura, su territorio y sus recursos naturales.

El marco jurídico nacional parte de la Constitución Política de Colombia, considerada pionera en América Latina en derechos de los grupos étnicos, y su art. 330, según el cual las decisiones sobre la materia se tomarán previa consulta con los representantes de tales comunidades (Orduz, 2014, p. 9). Continúa con la Ley 21 de 1991, "Por medio de la cual se aprueba el Convenio número 169 sobre pueblos indígenas y tribales en países independientes, adoptado por la 76a Reunión de la Conferencia General de la OIT, Ginebra 1989”. Y se consolida con la Ley 99 de 1993, también conocida como Ley General Ambiental, que en su art. 76 prevé, con relación a la explotación de los recursos naturales en los territorios de las comunidades 
indígenas y negras, que deberá hacerse sin desmedro de su integridad cultural, social y económica, de acuerdo con la Ley 70 de 1993, que desarrolla el art. transitorio 55 de la Constitución.

Al revisar las disposiciones normativas previstas desde 1980, al igual que lo contemplado en el art. 7 del Convenio 169 de la OIT, se encuentra que la consulta previa, es
el derecho que tienen los pueblos de decidir sus propias prioridades en lo que atañe al proceso de desarrollo, en la medida en que afecte a sus vidas, creencias, instituciones y bienestar espiritual y las tierras que ocupan o utilizan de alguna manera, y de controlar, en la medida de lo posible, su propio desarrollo económico, social y cultural. (Convenio 169, citado en Rodríguez, 2014, p. 37)

Por eso es pertinente que el Gobierno Nacional propicie la participación de los representantes de las respectivas comunidades antes de la realización de acciones de explotación en los territorios en los que se encuentren asentadas minorías reconocidas por la ley y la Constitución Política (C. N., citada en Orduz Salinas, p. 9). Al respecto cabe señalar que la mayor parte de las decisiones de la Corte Constitucional en este sentido enfatizan la importancia que la Constitución le ha dado a la diversidad étnica y cultural de la Nación (Orduz, p. 10).

La Sentencia T-428/1992, por su parte, señaló que la consulta previa constituye un derecho fundamental, individual y colectivo de los grupos étnicos, consistente en la posibilidad que tienen de decidir sobre las medidas legislativas o administrativas que los afecten directamente en la preservación de su integridad étnica, social, económica y cultural, así como en su subsistencia como grupo social (citada en Millán, Niño, Rincón y Rojas, 2010, p. 12).

En desarrollo de esta concepción la Corte Constitucional (Sentencia SU-039/1997) enfatizó en que el derecho fundamental de la comunidad a preservar la integridad se garantiza y efectiviza a través del ejercicio de otro derecho que también tiene carácter fundamental: el de la participación de la comunidad en la adopción de las referidas 
decisiones. De igual manera, y a través de otros fallos jurisprudenciales (sentencias SU-383/2003; T-769/2009), se determinó que la consulta previa es esencial para el mantenimiento de la cohesión social de los pueblos indígenas y las comunidades afrodescendientes.

Sin embargo, la Corte Constitucional (Sentencia T-485/2015) ha reconocido que existen ciertas circunstancias frente a las cuales la sola ejecución de un proceso consultivo orientado a alcanzar un acuerdo no garantiza que tal propósito se alcance. No basta pues con que se intente llegar a un acuerdo con las comunidades, es necesario que estas brinden su consentimiento sobre la medida correspondiente de forma libre, previa e informada.

En este mismo sentido, diferentes organismos de derechos humanos han denunciado violaciones al derecho de participación debido a que en ocasiones la consulta se ha llevado a cabo tras la concesión de proyectos, lo cual incumple su condición de previa (Indepaz, citado en López Martín, 2016, p. 23).

Por tal razón la Corte ha previsto en la Sentencia T-129/2011 que el momento oportuno para realizar la consulta debe ser antes de la adopción de medidas administrativas. No obstante, las comunidades han de tener la posibilidad de revisar y presentar sus puntos de vista sobre la intervención en su territorio no solo en la etapa previa, sino también durante y después de la ejecución de la obra o actividad (Lancheros Gámez y Burgos, citado en López Martín, 2016, p. 23).

Todo lo anterior tiene su fundamento en el derecho de la población raizal a conservar la propiedad sobre el territorio ancestral para efectos de que no continúe la pérdida progresiva de su cultura y organización social. Justamente por eso son objeto de especial protección por el Estado sustentada en su derecho a la autodeterminación (Ortiz, 2013, p. 33).

\section{El contexto del pueblo raizal en Colombia}

La isla de San Andrés fue poblada originalmente por los descendientes de colonos europeos y esclavos africanos, quienes a finales del siglo XVIII conformaron un 
asentamiento estable. De ellos descienden los raizales del archipiélago, quienes han mantenido constantes vínculos con otros pueblos del borde occidental del mar Caribe (Parsons, citado en Guevara, 2007, p. 296).

El origen del nombre de este grupo étnico se remonta a su relación y vínculo con el concepto de raíz. En inglés las raíces de los seres humanos tienen que ver con su linaje, es decir, su vínculo con una comunidad, un grupo étnico o un pueblo. Su razón de ser es describir las relaciones culturales ancestrales como la esencia misma de la herencia cultural de un pueblo (Forbes, p. 85).

Los raizales motivan sus reclamos de reconocimiento y respeto en su diferencia, su deseo de conservar una identidad propia. Este sentimiento de identidad insular y caribeña lo expresan a través de una serie de manifestaciones que caracterizan su personalidad con rasgos y comportamientos que evocan conjuntamente sus raíces africanas, europeas y caribeñas (Robinson, p. 6).

En ocasiones, y de modo forzoso, han sido catalogados como parte de la comunidad afro en virtud de que no existe una legislación que los reconozca oficialmente como una etnia con una cultura y cosmovisión propia (Torres, 2012, p. 50). Sin embargo, el territorio propio raizal lo constituyen islas, cayos e islotes comprendidos dentro del departamento del Archipiélago de San Andrés, Providencia y Santa Catalina (C. Const. Sentencia C-053/1999), y a pesar de los criterios previstos en sentencia de la Corte Internacional de Justicia que otorgó soberanía al Estado de Nicaragua sobre parte del territorio marítimo del archipiélago colombiano, los raizales le han otorgado un reconocimiento propio (Mow, Gallardo y Francis, citados en Peńa, 2015, p. 9). El mar para los nativos constituye gran parte de su territorio y es un centro ancestral de sus principales actividades económicas y culturales (Peña, 2015, p. 19).

Sin embargo, desde 2012 hasta 2017 el turismo se ha convertido en la principal actividad del archipiélago de San Andrés, Providencia y Santa Catalina debido al aumento de visitantes. Eso implica el incremento de todas las actividades que directa e indirectamente inciden en el viaje de las personas (Manjarrés y Rose, 2018, p. 17). 
Ahora bien, a diferencia de los indígenas y afrodescendientes, los raizales no han constituido propiedad colectiva, sino que han sido titulares de derechos de propiedad privada heredada de generación en generación sin que se admita con ello la comercialización de la tierra, por tradición familiar. Además, los raizales no cuentan con autoridades propias. Son la Alcaldía y el Concejo del municipio de Providencia y Santa Catalina los que ejercen la autoridad política y administrativa, de modo que se encargan de planificar las prioridades y el desarrollo. Sin embargo, ello no implica que se proteja el derecho de participación del pueblo raizal pues no existen garantías que aseguren la representación efectiva de los habitantes tradicionales de las islas en estas entidades (Peńa, 2015, p. 19).

\section{El derecho a la consulta previa para el pueblo raizal en Colombia}

A través de la Ley 21 de 1991 se dispuso que los pueblos indígenas y tribales, en virtud de su histórica discriminación, gozan de especial protección y particulares derechos fundamentales. Por ende, los gobiernos deben reconocer, proteger y responsabilizarse frente a cualquier tipo de vulneración que afecte su identidad, su cultura, sus costumbres y en conjunto su cosmovisión. En virtud de ello se establecen a través de la Ley 70 de 1993 mecanismos para la protección de la identidad cultural y los derechos de las comunidades negras de Colombia, también aplicables a los raizales como grupo étnico, bajo parámetros de equidad que llevan a que la consulta previa constituya un compromiso esencial e ineludible del Estado.

El territorio es sin duda uno de los elementos esenciales para la supervivencia de pueblos indígenas y tribales como el pueblo raizal. Al respecto, la Corte Constitucional (Sentencia SU-383/2003) ha considerado que su concepto definidor no se limita únicamente a una ocupación y apropiación del territorio y sus recursos, sino que además existen aspectos simbólicos a los que la identidad raizal se encuentra asociada (Sänger, 2015).

Por esa razón, el Estado consideró pertinente implementar dos medidas. En primera instancia, reconocer su derecho como minorías a un territorio colectivo en el que desarrollen su cultura y su proyecto de vida. En segundo lugar, en el marco de los procesos de delimitación territorial para exploración y explotación de recursos 
naturales en tierras comunales, garantizar la participación de los interesados en la adopción de medidas tendientes a desarrollar y proteger las formas de vida tradicionales a partir del reconocimiento de un concepto dinámico de territorio (C. Const. Sentencia T-849/2014). Por ende, en aquellos casos en los que el Estado o las organizaciones de carácter privado adopten decisiones que incidan en dichas formas de vida es imprescindible la participación de las comunidades afectadas mediante la realización de la consulta previa. (C. Const. Sentencia T-485/2015)

A la fecha y a través de la Sentencia SU-097/2017 la Corte dispuso que frente a la consulta previa la acción de tutela es el mecanismo preferente para la especial protección constitucional de los derechos de los pueblos. Esto evidencia que la dimensión constitucional de tales conflictos es particularmente intensa, en tanto no solo se refieren a los derechos fundamentales, sino a las bases del orden político establecido por el Constituyente de 1991.

\section{El caso del proyecto turístico Spa Providencia}

El proyecto turístico Spa Providencia ha sido uno de los casos más emblemáticos a través de los cuales la Corte Constitucional estableció un precedente fundamental del concepto de consulta previa para raizales y de cómo esta noción resulta ser el elemento esencial para que miembros de grupos étnicos, como el pueblo raizal, conozcan y participen de las políticas, directrices y decisiones que los afecten positiva o negativamente en la realización de proyectos turísticos. Adicionalmente, advirtió a las autoridades ambientales y jurisdiccionales sobre la importancia de interpretar adecuadamente ese concepto.

La Nación, el Mincit y el municipio insular de Providencia y Santa Catalina acordaron, a través del Convenio Interadministrativo 145 de 2011, aunar esfuerzos para elaborar los diseños arquitectónicos y técnicos del proyecto de infraestructura turística Spa Providencia, que se realizaría en el lote denominado Providencia South West. 
Al respecto, el Mincit consultó al Mininterior sobre el registro y la existencia de comunidades étnicas en el lote Providencia South West ${ }^{1}$. En respuesta, el Mininterior ${ }^{2}$ manifestó que sí se registraban comunidades raizales dentro del rango de influencia del proyecto y que, por ende, era necesario solicitar por escrito la realización de la consulta previa.

Por su parte, el Decreto 295 del 27 de febrero de 2013 estableció asignar recursos del Fondo de Promoción Turística para construir un spa en la isla de Providencia, que sería manejado por la población raizal. Igualmente, se implementaría un proyecto de apoyo a las posadas nativas.

En virtud de ello, el 30 de julio de 2013 y a través de la Veeduría Ciudadana Old Providence

la comunidad nativa raizal elevó derecho de petición ante Coralina (la Corporación Autónoma Regional local), la Procuraduría General y el Mininterior con el propósito de recolectar información acerca del proyecto Spa Providencia, toda vez que para ese momento no se había adelantado consulta previa y ya aquel había iniciado. Al respecto, el Mininterior informó que no se registraba en la Dirección de Consulta Previa de esta entidad información sobre la construcción del mencionado proyecto turístico.

Sin embargo, durante la primera semana de septiembre de 2013 el Mincit socializó el proyecto de Spa Providencia con la comunidad, a pesar de que no asistieron integrantes del pueblo raizal. En dicha reunión el Mininterior manifestó la no obligatoriedad de la consulta previa reiterando que ya el proyecto estaba en ejecución.

El 9 de septiembre de 2013 Coralina dio respuesta ${ }^{3}$ a la solicitud invocada por la Defensoría del Pueblo acerca de la naturaleza del lote en el que se adelantaba la construcción del proyecto. En esta respuesta dicha autoridad ambiental señala que

1 Radicado Ext11/40556 del 9 de mayo de 2011.

2 Oficio OFl11-20418-GCP-0201 del 19 de mayo de 2011.

3 Oficio COR/SPI 539. 
el predio South West Bay es una zona de protección ecológica en donde solo se pueden desarrollar actividades que estén dirigidas a la conservación, investigación y educación ambiental.

Como consecuencia de todo lo expuesto, miembros del grupo raizal cuestionaron a través de una acción de tutela el hecho de que se avalara la construcción de un proyecto en tierras pertenecientes a la comunidad sin la debida protección y participación de esta. Claramente, argumentaban, ello impedía el pleno ejercicio de su identidad cultural, sus actividades económicas y sus manifestaciones culturales dentro de su territorio.

Por eso, a juicio de la accionante, la situación generaba una afectación a la comunidad porque el spa no permitía el desarrollo de sus actividades de una manera normal y la construcción modificaba el territorio sin tener en cuenta los efectos que podían generarse. (C. Const. Sentencia T-800/2014, p. 5)

En tal sentido, la accionante solicitó expresamente:

Se ordene la suspensión inmediata de las obras adelantadas del proyecto [...]; la realización inmediata y efectiva del proceso de consulta previa con la participación activa de la comunidad raizal bajo sus usos y costumbres [...]; que se incluya tal como señala el proyecto "Spa en providencia" a los habitantes nativos de la zona dentro del manejo y funcionamiento del futuro complejo hotelero y turístico [...] y que se haga, a responsabilidad del Ministerio del Interior, una capacitación a los integrantes de la Comunidad Nativa Raizal sobre la consulta. (C. Const. Sentencia T-800/2014, p. 6)

Con base en los argumentos invocados la Sala Única del Tribunal Superior del Distrito Judicial de San Andrés, Providencia y Santa Catalina, en Sentencia del 3 de abril de 2014, desestimó su protección argumentando que el ente ministerial

agotó los mecanismos necesarios para llevar a cabo la consulta previa, es decir que actuó de manera adecuada para procurar que la comunidad conociera el contenido del proyecto, pero ante el concepto ofrecido por el Ministerio de 
Justicia que no requería la consulta, procedieron a llevar adelante el proyecto [...] por consiguiente no se avizora ningún quebrantamiento a los derechos fundamentales alegados.

De igual manera, dicho tribunal basó su fallo en el principio de confianza legítima manifestando que frente al proyecto Spa Providencia no era necesario llevar a cabo la consulta previa, toda vez que la intención de sus promotores era contribuir positivamente al desarrollo económico de la comunidad raizal sin afectar su idiosincrasia cultural. Además, señaló que el proyecto era de carácter turístico y no de explotación de recursos naturales, en cuyo caso sí se hubiera requerido la consulta (Sentencia, 2014, pp. 7-8).

Inconforme con el fallo del Tribunal Superior la comunidad llevó el caso a segunda instancia siendo asumido por la Sala de Casación Civil de la Corte Suprema de Justicia. Esta encaminó su posición señalando que existían otros mecanismos, tales como las acciones de grupo o populares, que de no ser favorables permitirían al pueblo raizal reclamar la presunta violación de derechos fundamentales a través de la acción de tutela como requisito de subsidiaridad.

Finalmente el caso llegó a la revisión por parte de la Corte Constitucional, que al respecto, y contrario sensu a lo planteado por las dos instancias mencionadas, en la Sentencia T-800 de 2014 manifestó que la consulta previa era procedente frente al caso concreto debido a la presencia fácilmente verificable de comunidades en la isla, y específicamente en la zona en la que se pretendía desarrollar el proyecto.

En este fallo el máximo tribunal constitucional reiteró que la referida comunidad es un grupo étnico establecido en Colombia, que goza plenamente de los derechos garantizados para otras etnias, con especial protección a su territorio como propio de la jurisdicción del departamento Archipiélago de San Andrés, Providencia y Santa Catalina (Ambiente y Sociedad, 2015).

Manifestó además la Corte que tanto la respuesta del Tribunal como la de la Corte Suprema de Justicia distan de los fines preceptuados en el Convenio 169 sobre el concepto de consulta previa. En efecto, el art. 7 de tal compendio, relacionado con 
pueblos indígenas y tribales, establece que a dichos grupos se les debe consultar sobre las determinaciones que afecten sus intereses, sus derechos y su cultura sin señalar salvedades que impliquen distinción respecto de si el efecto es positivo o no, o si es imprescindible agotar acciones que protejan derechos colectivos antes de invocar la acción de tutela.

Sumado a ello, se aclaró, el hecho de que el proyecto Spa Providencia no estuviera relacionado con la explotación de recursos naturales no implicaba que no generara un impacto significativo en la comunidad. Adicionalmente, las medidas administrativas en las que se pruebe afectación de cualquier tipo a un grupo étnico deben ser consultadas antes de su adopción con el fin de proteger la integridad étnica y cultural del grupo. $Y$ es el derecho de consulta previa el que se ha establecido para todas las decisiones que tengan incidencia de ese tipo, sin distinción alguna, incluidos los proyectos de desarrollo turístico.

Así mismo, se enfatizó que la consulta previa es un derecho fundamental de los grupos étnicos y la acción de tutela, el único mecanismo por medio del cual pueden reclamarla y de ese modo preservar y asegurar su integridad étnica, social, económica y cultural como grupo (Corte Constitucional, 2007, citada en C. Const. Sentencia T-800/2014). La consulta previa, señala la Corte, no es un mero mecanismo de defensa, sino uno de participación que le permite a este tipo de grupos obtener conocimiento sobre los proyectos y su ejecución para efectos de establecer su posición sobre las ventajas y desventajas de su realización (C. Const. Sentencia T-800/2014).

Por ende, no es necesario, como manifestó en su momento la Sala de Casación de la Corte Suprema de Justicia, condicionar la realización de la consulta a un previo derecho de petición de la comunidad raizal, cuando es a las autoridades a las que les compete identificar a las comunidades afectadas por un proyecto o una medida legislativa. De no procederse de ese modo se estaría generando una carga adicional para la comunidad que esta no tendrían por qué soportar.

Como resultado de todo lo expuesto la Corte concluyó que la acción de tutela no solo resultaba procedente frente al caso concreto, sino que además implicaba la 
suspensión de la obra Spa Providencia hasta tanto se diera cumplimiento al requisito fundamental de la consulta previa en presencia de los representantes de la comunidad raizal.

A raíz de la correspondiente decisión se reunieron los miembros de la referida comunidad y representantes del Mininterior, Coralina, la Defensoría del Pueblo (nacional y regional), la Alcaldía de Providencia y un profesional de Fontur encargado de explicar las actividades desarrolladas en el proyecto Spa Providencia, con el fin de suscribir un acta denominada "Proceso de consulta previa con la comunidad nativa raizal de Providencia y Santa Catalina ordenado por la Corte Constitucional mediante Sentencia T-800 de 2014 para el proyecto Spa Providencia”. En esta se consignó que

durante el proceso de consulta previa, los miembros de la comunidad expresaron su consentimiento para que el ejecutor continuara con los trámites y demás procedimientos relacionados con su ejecución, de acuerdo con lo dispuesto en la ley y la jurisprudencia vigente. (Mininterior, 2015, p. 18)

En este orden de ideas, la Sentencia T-800/2014 establece la necesidad de que la consulta previa se realice con antelación a la materialización de cualquier proyecto turístico que pueda incidir en el desarrollo integral y cultural de un determinado grupo étnico de especial protección, como ocurrió en el caso del pueblo raizal ubicado en el municipio de Providencia.

\section{ConClusiones}

El Caribe colombiano se destaca por ser un atractivo para millones de turistas. Actualmente el turismo constituye uno de los principales renglones de la economía en muchos Estados caribeños, en particular en las pequeñas islas que se han dedicado a esta industria. Eso lo ha convertido en el principal y más importante factor de transformación social y de revitalización económica de las comunidades costeras, al punto de desplazar actividades tradicionales, como la pesca y la silvicultura. Sin embargo, el ecosistema de la región Caribe, tiene además de lo económico una fuerte 
representación cultural, espiritual y recreacional para los habitantes de las zonas costeras pues existe un vínculo intrínseco entre su cultura, su construcción social y familiar, por un lado, y el medio marino, por otro (Breton, Yyan y Corte IDH, citados en GAP, 2016, pp. 6-7).

Por eso es imprescindible que en el desarrollo de proyectos turísticos en esta región el Estado junto con el sector privado formulen conjuntamente estudios de impacto y posibles consecuencias para el ambiente de la zona, al igual que análisis de las repercusiones que estas iniciativas puedan llegar a ocasionar en las condiciones de vida de los habitantes (GAP, 2016, p. 23).

Ahora bien, los efectos del turismo en el entorno natural de la comunidad raizal son particularmente complejos. En efecto, de acuerdo con ONU Ambiente (Programa de las Naciones Unidas para el Medio Ambiente y el Desarrollo), el crecimiento de la actividad turística se encuentra allí unido a la presencia de problemas ambientales como sobrepoblación de fuentes acuíferas, contaminación de arroyos y del mar (en el caso de las islas), sobreexplotación de la infraestructura natural (playas, arrecifes, etc.) y destrucción del patrimonio natural (Peña, 2014).

Estas situaciones se deben en gran medida a que la cultura del pueblo raizal es diferente a la del resto de los colombianos, particularmente en materia de lengua, religión y costumbres, que le confieren al raizal una cierta identidad (C. Const. Sentencia C-530/1993).

Sin embargo, no obstante la diferencia entre los criterios de los inversionistas y los de los miembros de estas minorías, se concluye que sus objetivos pueden conciliarse, en la medida en que los conceptos relacionados con la consulta previa se clarifiquen y apliquen conforme lo establecen la ley y la jurisprudencia.

Las entidades públicas, tienen una gran responsabilidad y participación en este tipo de procesos por ser las principales garantes de protección de derechos fundamentales y colectivos de las comunidades raizales. Al fin y al cabo son las encargadas de determinar la presencia de proyectos en los territorios de tales grupos, o sus alrededores, que puedan afectarlos de modo significativo. Igualmente tienen 
el deber de supervisar la elaboración de los estudios de impacto previstos por la legislación nacional para efectos de tomar las medidas de protección adecuadas y adelantar el procedimiento de consulta previa de acuerdo con los estándares legales y jurisprudenciales vigentes.

Así las cosas, es deber del Estado, como garante de derechos de las comunidades raizales y protector del ambiente que las rodea, emprender acciones de índole preventivo, durante y con posterioridad a los procesos de consulta para efectos de verificar el cumplimiento de los acuerdos previstos por los interesados y posibles afectados.

Esto con el fin de que los miembros de las comunidades raizales participen, consideren, acuerden y decidan a favor o en contra del desarrollo de un determinado proyecto turístico que pueda afectarlos, antes de que se presente cualquier tipo de vulneración de sus derechos, como se determinó que ocurrió en el caso del fallo T-800 de 2014. Mediante este, recuérdese, la Corte Constitucional resolvió el asunto determinando que la consulta previa es sin lugar a dudas un derecho fundamental que le asiste a la comunidad raizal, independientemente de si los efectos que se generen resultan positivos o no, enfatizando en que el único mecanismo a través del cual a dichas minorías les es posible reclamar es a través de la acción de tutela, aún tratándose de una colectividad.

En virtud del contenido previsto en la decisión en cita, el 16 de diciembre de 2014 las partes intervinientes en el proceso suscribieron un acta mediante la cual se buscaba dar cumplimiento a la Sentencia T-800 de 2014. Se suscribieron entonces acuerdos relacionados con la aplicación de los parámetros legales; el acompañamiento de expertos en el manejo del spa; el manejo eficiente de los recursos naturales e hídricos por parte de las autoridades estatales; la conservación y promoción del cangrejo negro y la formulación de los términos de referencia básicos para la elaboración de la convocatoria que definiría el operador raizal del proyecto Spa Providencia por parte de la comunidad nativa, entre otros aspectos. 


\section{REFERENCIAS}

Ambiente y Sociedad (2015). Fallo histórico sobre consulta previa para raizales en Spa Providencia. Recuperado de https://tinyurl.com/yxg7kw9t

Brida, J. G., Monterubbianesi, P. D. y Zapata-Aguirre, S. (2011). Impactos del turismo sobre el crecimiento económico y el desarrollo. El caso de los principales destinos turísticos de Colombia. Pasos. Revista de Turismo y Patrimonio Cultural, 9(2), 291-303. DOI: https://doi.org/10.25145/j.pasos.2008.06.036

CIDH (Comisión Interamericana de Derechos Humanos). (2010). Derechos de los pueblos indigenas y tribales sobre sus tierras ancestrales y recursos naturales. Recuperado de https:// www.oas.org/es/cidh/indigenas/docs/pdf/tierras-ancestrales.esp.pdf

Corte Constitucional. Sentencia T-428 (24 de junio de 1992). M. P. Ciro Angarita Barón.

Corte Constitucional. Sentencia C-530 (11 de noviembre de 1993). M. P. Alejandro Martínez Caballero.

Corte Constitucional. Sentencia SU-039 (3 de febrero de 1997). M. P. Antonio Barrera Carbonell.

Corte Constitucional. Sentencia C-053 (2 de febrero de 1999). M. P. Eduardo Cifuentes Muñoz.

Corte Constitucional. Sentencia SU-383 (13 de mayo de 2003). M. P. Álvaro Tafur Galvis.

Corte Constitucional. Sentencia T-769 (29 de octubre de 2009). M. P. Nilson Pinilla Pinilla.

Corte Constitucional. Sentencia T-129 (3 de marzo de 2011). M. P. Jorge Iván Palacio Palacio.

Corte Constitucional. Sentencia T-800 (31 de octubre de 2014). M. P. Gabriel Eduardo Mendoza Martelo. 
Corte Constitucional. Sentencia T-849 (12 de noviembre de 2014). M. P. Martha Victoria Sáchica Méndez.

Corte Constitucional. Sentencia T-485 (5 de agosto de 2015). M. P. Myriam Ávila Roldán.

Corte Constitucional. Sentencia SU-097 (16 de febrero de 2017). M. P. María Victoria Calle Correa.

Cortés, S. (2013). La globalización económica y los derechos humanos. Via Inveniendi et Iudicandi, 8(2), 138-149. DOI: https://doi.org/10.15332/s1909-0528.2013.0002.06

Cortés, S. (2016). Derechos humanos en las políticas de paz y posconflicto en Colombia. Via Inveniendi et Iudicandi, 11(1), 129-145. DOI: https://doi.org/10.15332/ s1909-0528.2016.0001.03

Corte Suprema de Justicia, Sala de Casación Civil (23 de mayo de 2014). Sentencia. DOI: https://doi.org/10.15332/s1900-0448.2012.0036.03

Cubillos, C ., González, C., Díaz, E., Ruiz, F. y Jiménez, Z. (2013). Guía para la planificación del ecoturismo en parques nacionales naturales de Colombia. Bogotá: PNNC/Minambiente/Metsähallitus/ Formin Finland.

DNP (Departamento Nacional de Planeación). (2015). Plan Nacional de Desarrollo 20142018. Todos por un mejor país. DOI: https://doi.org/10.17533/udea.le.n89a06

Diario de San Andrés y Providencia (2016). El pueblo raizal y la geopolítica Caribe. El Isleño. Recuperado de https://goo.gl/4wXoEZ

Forbes, O. (2005). Multiculturalismo \& multilingüismo: un análisis de la microfísica y la geopolítica de las culturas y lenguas en contacto y en conflicto en San Andrés Isla. Revista Anaconda, 6, 64-93.

GAP (Grupo de Acciones Públicas). (2016). Escrito de intervención en relación con la solicitud de opinión consultiva presentada por la República de Colombia frente a los artículos 1.1, 4 
y 5 de la Convención Americana de Derechos Humanos. Bogotá: Universidad del Rosario. DOI: https://doi.org/10.22201/iij.9786073002516p.2018

García Hernández, O. (2013). Interpretación Socioambiental (ISA), Herramienta para la gestión del uso público en las áreas protegidas. Estudio de caso: Parque Nacional Marino Las Baulas de Guanacaste, Costa Rica. Anuario Turismo y Sociedad, 14, pp. 103-120. DOI: https://doi.org/10.4995/thesis/10251/29892

Gómez Tobón, J. (2002). Turismo, conflicto armado y paz en Colombia: apostándole al futuro. Turismo y Sociedad, 1, 57-69.

Guevara, N. (2007). San Andrés Isla, memorias de la colombianización y reparaciones. En C. Rosero-Labbé (comp.), Afrorreparaciones: memorias de la esclavitud y la justicia reparativa para negros, afrocolombianos y raizales (pp. 295-317). Bogotá: Instituto de Estudios Caribeños, Universidad Nacional de Colombia. DOI: https://doi. org/10.25058/20112742.300

Güiza, L. y Gutiérrez, L. (2012). El papel de las autoridades ambientales en la resolución de los conflictos: un enfoque desde los derechos humanos. En B. Londońo, L. Güiza y L. Muñoz (eds.), Conflictos ambientales en Colombia. Retos y perspectivas desde el enfoque de DD. HH. y la participación ciudadana (pp. 91-103). Bogotá: Universidad del Rosario. DOI: https://doi.org/10.2307/j.ctt1w76sz9.8

Humbarita, J. (2015). Derecho constitucional hispanoamericano frente a la realidad institucional, manifiesta divergencia. Revista Iusta, 43(2), 91-118. DOI: https://doi. org/10.15332/s1900-0448.2015.0043.03

López, C. (2015). Empresas y derechos humanos: hacia el desarrollo de un marco jurídico internacional. Aportes DPLf, 8(20), 4-6. Recuperado de https://goo.gl/2RwpmZ

López Martín, C. (2016). El derecho fundamental a la consulta previa de las comunidades indígenas: un estudio comparado entre Colombia y Perú desde un enfoque territorial (tesis de grado). Universidad Católica de Colombia, Bogotá. DOI: https://doi.org/10.2307/j. ctt1w76t1t.6 
Millán, C., Niño, M., Rincón, J. y Rojas, P. (2010). Protección a la consulta previa: derecho fundamental de las minorias contra el interés colectivo. Inédito. Recuperado de https://goo. gl/1LgF9x

Mininterior (Ministerio del Interior, República de Colombia) (2015). Acta Proceso de consulta previa con la comunidad nativa raizal de Providencia y Santa Catalina ordenado por la Corte Constitucional mediante Sentencia T-800 de 2014 para el proyecto Spa Providencia. DOI: https://doi.org/10.5354/0719-5249.1972.34666

M\&S Consultants. (2018). Estudio económico San Andrés, Providencia y Sta. Catalina 2017. Cámara de Comercio de San Andrés, Providencia y Santa Catalina. DOI: https:// doi.org/10.18235/0000520

OMT (Organización Mundial del Turismo). (1994). Entender el turismo: glosario básico. Recuperado de https://tinyurl.com/hyz2f5d

OMT (Organización Mundial del Turismo). (2012). Desarrollo sostenible del turismo. Recuperado de https://tinyurl.com/y4kctwe2

OIT (Organización Internacional del Trabajo). (2012). Convenio 169. El derecho a la consulta. Lima: OIT. DOI: https://doi.org/10.1111/j.1564-9148.2014.00199.x

Orduz Salinas, N. (2014). La consulta previa en Colombia. Documento de trabajo ISCO-No 3/2014. Santiago: Instituto de Investigación en Ciencias Sociales UDP. Recuperado de https://tinyurl.com/yygu3p8u

Ortiz, F. (2013). Los derechos del pueblo raizal del archipiélago más allá del fallo de la Corte Internacional de Justicia de La Haya. Cuadernos del Caribe, 10(16), 27-36. DOI: https:// doi.org/10.22201/iij.24484873e.2015.142.4931

Peña, A. (28 de agosto de 2014). El plan de San Andrés y la amenaza del turismo foráneo en las islas de Providencia y Santa Catalina. Actualidad Étnica. DOI: https://doi. org/10.18235/0000520 
Peña, A. (2015). Limites del ordenamiento ambiental del territorio al turismo: el caso del aeropuerto internacional en la isla de Providencia (monografía de grado). Universidad del Rosario, Bogotá. DOI: http://lunazul.ucaldas.edu.co/index.php?option=content\&task= view\&id=1010

Rivera, G. (27 de febrero de 2016). Las empresas y los derechos humanos. La protección de los derechos humanos no es exclusiva del Estado, también de la sociedad civil. El Tiempo. DOI: https://doi.org/10.4000/books.uec. 1480

Robinson, D. (s. f.). Pueblo raizal en Colombia. Bogotá: Universidad del Rosario. Recuperado de https://tinyurl.com/yyh3pwx3

Rodríguez, G. (2014). De la consulta previa al consentimiento libre, previo e informado a pueblos indigenas en Colombia. Bogotá: Universidad del Rosario. DOI: https://doi. org/10.12804/tj9789587389081

Romero, A. et al., (2016). Consulta previa y modelos de desarrollo: juegos de espejos. Bogotá: Gente Nueva.

Sänger, R. (2015). La garantía de la propiedad y el principio de proporcionalidad como límites de la carga tributaria en Alemania. Revista Iusta, 42(1), 73-99. DOI: https://doi. org/10.15332/s1900-0448.2015.0042.04

Swarbrooke, J. (1999). Sustainable tourism management. Recuperado de https://goo.gl/ okhKMv

Torres, M. (2012). La etnia raizal del archipiélago de San Andrés, Providencia y Santa Catalina frente a la Constitución de Colombia: elementos jurídicos para discusión. Bogotá: Universidad del Rosario. DOI: https://doi.org/10.18235/0000520

Tribunal Superior del Distrito Judicial de San Andrés, Providencia y Santa Catalina. Sala Única. Sentencia (3 de abril de 2014). 
VIeI $\begin{aligned} & \text { Revista Virtual } \\ & \text { Via Inveniendi et Iudicandi }\end{aligned}$

Varisco, C. (2008). Economía, desarrollo turístico y desarrollo local: la competitividad de los destinos turísticos de sol y playa (tesis de maestría). Universidad Nacional de Mar del Plata, Buenos Aires.

(c) (i) (O) 